\title{
Lot-sizing and pricing decisions for perishable products under three-echelon supply chains when demand depends on price and stock-age
}

\author{
Ruihai $\mathrm{Li}^{1}$ - Jinn-Tsair Teng ${ }^{2,3}$ (D) Chun-Tao Chang ${ }^{4}$
}

Accepted: 14 September 2021 / Published online: 6 October 2021

(c) The Author(s), under exclusive licence to Springer Science+Business Media, LLC, part of Springer Nature 2021

\begin{abstract}
In economics, a demand curve is almost always downward-sloping, reflecting the willingness of consumers to purchase more of the commodity at lower price levels. In addition, the demand for seasonal products (such as fashion apparels, beverages etc.) or perishable goods (such as meat and seafood, dairy products, fruit and vegetables, pharmaceutical products, and chemicals) decreases over time. Hence, demand is a function of price and stock-age. With large business transactions, a seller usually demands a down payment (i.e., an advance payment) to ensure that the buyer is making a serious offer. Conversely, a buyer frequently requests to hold a fraction of total purchase cost until the business transaction is completed and satisfactory (i.e., a credit payment). As a result, a combination of advance, cash, and credit (ACC) payments is commonly used in business transactions. This paper develops a supplier-retailer-customer chain in which the retailer receives an upstream ACC payment from the supplier while in return offers a down-stream cash-credit (some in cash and the remainder in credit) payment to customers, the demand is influenced by the combined effect of selling price and stock age, and the deterioration rate is time-varying. The retailer must determine optimal unit price and replenishment time to maximize the present value of total profit, which is strictly concave in selling price and strictly pseudo-concave in replenishment time. Finally, a sensitivity analysis is performed, and several managerial insights are obtained.
\end{abstract}

Jinn-Tsair Teng

tengj@wpunj.edu

Ruihai Li

lirh@lixin.edu.cn

Chun-Tao Chang

chuntao@mail.tku.edu.tw

1 School of Business Administration, Shanghai Lixin University of Commerce and Finance, Shanghai, China

2 Department of Marketing and Management Sciences, The William Paterson University of New Jersey, Wayne, NJ 07470, USA

3 Department of Business Administration, Chaoyang University of Technology, Taichung, Taiwan, ROC

4 Department of Statistics, Tamkang University, Tamsui, Taipei, Taiwan 
For instance, an increase in the fraction of advance payment forces the retailer to raise selling price.

Keywords Supply chain · Price-and-age-dependent demand · Advance-cash-credit payments $\cdot$ Discounted cash-flow analysis

\section{Introduction}

When the purchase of expensive items such as a house and a yacht, the seller usually asks the buyer to: (i) prepay an upfront portion of the total cost as a down payment or an escrow deposit when signing a contract to buy the items (i.e., an advance payment), then (ii) pay another portion of the total cost in cash upon receiving the items (i.e., a cash payment), and finally (iii) receive a short-term interest-free credit term (i.e., a credit payment) for the remainder of the total cost. In fact, this advance-cash-credit payment scheme is commonly used in real-world business transactions. For instance, a roofing and remodeling firm usually asks a customer to pay an upfront portion of the total cost as an advance down payment when signing a business proposal to install a new roof or to pave a driveway. Upon delivery of the materials to do the job, a cash on delivery is then required to cover the materials cost. Finally, the customer will pay the remainder of the total cost after the work is completed and satisfactory. Although ACC payment is commonly used and includes advance, cash, credit, and many other types of payments as special cases, only a few studies in the literature have explored an ACC payment scheme until now.

In economics, it is well known from the law of demand that the demand of a given product or service decreases as its price increases, and vice versa. Likewise, the demand for seasonal products (such as fashion apparels, beverages etc.) or perishable goods (such as meat and seafood, dairy products, fruit and vegetables, pharmaceutical products, and chemicals) decreases as time goes on. Furthermore, a consumer can feel weather changes to judge the age of seasonal products. Similarly, a health conscious consumer can read the expiration date to know the age of perishable goods. As a result, the demand rate of a seasonal or perishable product depends on both selling price and stock age. However, most studies in the existing literature assume that perishable goods deteriorate continuously and could be sold forever without taking expiration date into consideration. Failing to consider the effect of expiration date on demand may lead to a biased solution and thus explicit study on the effect of expiration date is necessary.

According to scientists and natural health experts, the consumption of seasonal or perishable fruits and vegetables benefits us all, from local economic sustainability and reduced costs for producers, to lower prices for consumers and enhanced health benefits. In addition, the grocery sales in the United States contains 50\% perishable foods, 30\% nonperishable foods, and $20 \%$ nonfood items as reported by First Research (2013). Hence, seasonal and perishable products have become increasingly important sources of revenue in the grocery industry. In this paper, we investigate an inventory model interfaced with finance, marketing, and operations in a three echelon supplier-retailer-consumer chain in which: (1) the demand curve for a seasonal or perishable product is downward sloping of unit price and stock age, (2) the retailer receives an ACC payment from the supplier while offering a cash-credit payment (i.e., some in cash payment and the remainder in credit payment), (3) the deterioration rate of perishable goods is time-varying, and (4) the analysis takes time value of money into consideration by using a discounted cash-flow analysis. The retailer's objective is to find the 
optimal selling price and replenishment time simultaneously in order to maximize the present value of total profit.

In the literature review on payment types, Harris (1913) used a cash payment to develop the traditional economic order quantity (EOQ) inventory model in order to obtain the optimal order quantity. To capture the fact that a seller frequently offers a buyer a permissible delay in payment to increase sales, Teng (2002) adopted a credit payment to derive optimal order quantity. The reader is referred to the detailed review by Seifert et al. (2013). Zhang (1996) suggested an advanced payment for a customer to save time and money by prepaying $\$ 150$ for 3-month water bills instead of paying $\$ 50$ each month. To reduce the risk that creditrisk consumers will be unable to make the required payments on their debt obligations, Teng (2009) proposed a cash-credit payment. Taleizadeh (2014) explored an advance-cash payment (i.e., some in advance payment and the remainder in cash payment) to study the situation in which a gasoline supplier asks a gas station to pay a portion of the purchase cost upfront when placing an order and then to pay the remainder in cash on delivery. Concurrently, Zhang et al. (2014) investigated an advance-credit payment (i.e., some in advance payment and the remainder in credit payment) to capture the facts that a seller utilizing a partial advance payment to avoid the risk of buyer's order cancellation, and a permissible delay in payment to induce more sales. Wu et al. (2018a) introduced a generalized ACC payment to include advance, cash, credit, advance-cash, advance-credit, and cash-credit payments as special cases. Mishra et al. (2018) proposed joint pricing, lot-sizing, and preservation technology investment policies for deteriorating items under permissible delay in payments. Jaggi et al. (2019) studied a supplier-retailer supply chain in which demand for the products is displayed stock dependent and obtained the optimal decisions of the supply chain under three different policies: centralized policy, Supplier-led Stackelberg solution, and Nash equilibrium solution. Recently, Cárdenas-Barrón et al. (2020) established an EOQ model with nonlinear holding cost and demand rate under various trade credits. Shi et al. (2020) integrated three payment types and inventory decisions under sustainability issues to reduce carbon emissions. Concurrently, Feng et al. (2020) discussed optimal selling price, replenishment cycle, and payment time among advance, cash and credit payments from the seller's perspective.

It is evident that the demand for a perishable (or seasonal) product decreases over time due to loss of product freshness (or trendiness). In the existing literature, research in the field of deteriorating items or perishable goods has been extensive. For detailed reviews in this research area, the reader is referred to the works of Bakker et al. (2012), Pahl and Voß (2014), Wang and Huang (2014), and Chen and Xiao (2017). In reality, health-conscious consumers can easily evaluate the freshness of a perishable product by reading its expiration date. As a result, rational consumers prefer a perishable product further from its expiration date because it is fresher and can be stored longer. Thus, the demand rate for a perishable product gradually decreases with time and reaches zero at its expiration date. However, most studies in the literature assume that perishable products deteriorate continuously and could be sold indefinitely without considering the expiration date. To complement this shortcoming, Sarkar (2012) developed an EOQ model with an inversely linear deterioration rate which captures the fact that the rate of deterioration gradually increases to $100 \%$ as its expiration date approaches. Sequentially, Chen and Teng (2014, 2015), Dye et al. (2014), Teng et al. (2016), Wang et al. (2014), Wu et al. (2014, 2018a, 2018b) adopted the same rate of deterioration to investigate a variety of inventory models under various credit terms. Lately, Wu et al. (2016) proposed a demand pattern to be linearly declining to zero when it is approaching the expiration date. Chen et al. (2016) further expanded the freshness-and-stock-dependent demand to consider the shelf space as another decision variable. On the other hand, Li et al. (2017) explored a similar demand pattern by adding a pricing strategy. Furthermore, Li and Teng (2018) 
studied pricing and lot-sizing policies when demand depends on selling price, reference price, product freshness, and displayed stocks. Currently, Tiwari et al. (2020) obtained the retailer's optimal ordering policy for deteriorating items under order-size dependent trade credit. Gupta et al. (2020) explored ordering policies for time-varying deteriorating items with partial backlogging and permissible delay in payments in a two-warehouse environment. Lately, Xie et al. (2021) formulated a joint inspection and inventory model for deteriorating items with time-dependent demand and deteriorating rates. In summary, a brief comparison among the above-mentioned models is given in Table 1 .

If the simple interest rate is 5\%, then $\$ 100$ today is worth $\$ 105(=\$ 100 * 1.05)$ a year later. Conversely, $\$ 105$ a year from now is equivalent to $\$ 1000(=\$ 1050 / 1.05)$ today. Similarly, if the annual compound interest rate is $r$ per dollar per year, then $\$ 100$ today is worth $\$ 100 e^{r}$ a year from now. Conversely, $\$ 100$ a year from now is equivalent to $\$ 100 e^{-r}$ now. The fundamental difference among advance, cash and credit payments is payment timing which affects time value of money on purchase cost. Thus, the proper way to calculate three different payments is to conduct a discounted cash-flow analysis. However, most studies in the literature related to three different payments adopt discounted cash-flow analysis only on purchase cost but not on sales revenue (which is significantly larger than purchasing cost) or on any other costs. For a rigorous and sound analysis, this study adopts a discounted cash-flow analysis on both sales revenue and all costs. Following Chen and Teng (2015), a discounted cash-flow analysis is used to set up the objective that maximizes the retailer's present value of total annual profit. In addition, the model is formulated in order to capture the important and relevant fact that demand for perishable goods gradually declines over time and reaches zero as its expiration date approaches. Moreover, it is adopted a generalized ACC payment scheme which includes all six commonly used payment types as special cases. Furthermore, the present value of total annual profit is demonstrated that is strictly pseudo-concave in both the selling price and the replenishment time. This theoretical result simplifies the search for the global solution to a local maximum. Finally, several numerical examples are solved by a discounted cash-flow analysis to gain managerial insights.

The remainder of this paper is organized as follows. Section 2 defines the notation and assumptions used throughout this paper. Section 3 develops mathematical models for different cases. Section 4 derives the theoretical results and optimal solutions under certain conditions. Section 5 solves numerical examples by a discounted cash-flow analysis and performs a sensitivity analysis to gain managerial insights. Finally, Sect. 6 gives some conclusions and future studies.

\section{Notation and assumptions}

The following notation and assumptions are introduced to develop the inventory model for a perishable product in which quality deteriorates due to environmental conditions through time, such as meat and meat by-products, fish and seafood, dairy products, fruit and vegetables, flowers, pharmaceutical products, and chemicals.

\subsection{Notation}

The following parameters, functions, and decision variables are used in establishing the model. 
Table 1 A brief review of related literature

\begin{tabular}{|c|c|c|c|}
\hline References & Payment type & Demand function & Deterioration \\
\hline Chang et al. (2019) & $\mathrm{ACC}$ & Price & Time-varying \\
\hline Cárdenas-Barrón et al. (2020) & Credit & Nonlinear & No \\
\hline Chen et al. (2016) & Cash & Stock age and level & Linear \\
\hline Chen and Teng (2015) & Credit & Credit period & Time-varying \\
\hline Dye et al. (2014) & Credit & Credit period & Time-varying \\
\hline Feng and Chan (2019) & Cash & Price & No \\
\hline Feng et al. (2017) & Cash & $\begin{array}{l}\text { Price, stock age, and stock } \\
\text { level }\end{array}$ & No \\
\hline Feng et al. (2020) & $\mathrm{ACC}$ & Price & No \\
\hline Gupta et al. (2020) & Credit & Constant & Time-varying \\
\hline Harris (1913) & Cash & Constant & No \\
\hline Jaggi et al. (2019) & Credit & Stock level & Constant \\
\hline Li et al. (2017) & $\mathrm{ACC}$ & Price & Time-varying \\
\hline Li and Teng (2018) & Cash & $\begin{array}{l}\text { Price, stock age, and stock } \\
\text { level }\end{array}$ & No \\
\hline Li et al. (2018) & ACC & Payment timing & No \\
\hline Li et al. (2019a) & ACC & Price & No \\
\hline Li et al. (2019b) & Credit & $\begin{array}{l}\text { Price, stock age, and credit } \\
\text { period }\end{array}$ & Time-varying \\
\hline Mishra et al. (2018) & Credit & Price & Preservation-tech \\
\hline Modak and Kelle (2019) & Cash & Price and delivery & No \\
\hline Sarkar (2012) & Credit & Constant & Inverse-linear \\
\hline Shi et al. (2020) & $\mathrm{ACC}$ & Constant & Time-varying \\
\hline Taleizadeh (2014) & Advance-cash & Constant & Constant \\
\hline Teng (2002) & Credit & Constant & No \\
\hline Teng (2009) & Cash-credit & Constant & No \\
\hline Teng et al. (2016) & Cash & Constant & Inverse-linear \\
\hline Tiwari et al. (2020) & Credit & Constant & Constant \\
\hline Wang et al. (2014) & Credit & Credit period & Inverse-linear \\
\hline Wu et al. (2014) & Credit & Credit period & Inverse-linear \\
\hline Wu et al. (2016) & Cash & Stock age and level & Linear \\
\hline Wu et al. (2018a) & $\mathrm{ACC}$ & Constant & Inverse-linear \\
\hline Xie et al. (2021) & Cash & Time-varying & Time-varying \\
\hline Zhang (1996) & Advance & Constant & No \\
\hline Zhang et al. (2014) & Advance-credit & Constant & Constant \\
\hline This paper & $\mathrm{ACC}$ & Price and stock age & Time-varying \\
\hline
\end{tabular}




\subsubsection{Parameters}

$\alpha$ The fraction of total purchase cost to be paid in advance, $0 \leq \alpha \leq 1$

$\beta$ The fraction of total purchase cost to be paid at the time of delivery, $0 \leq \beta \leq 1$

$\chi$ The fraction of total purchase cost granted a permissible delay from the supplier to the retailer, $0 \leq \chi \leq 1$ and $\alpha+\beta+\chi=1$

$\delta$ The downstream credit period by the retailer to customers, $\delta \geq 0$

$\mu$ The upstream credit period by the supplier to the retailer, $\mu \geq 0$

$\rho$ The fraction of the sales revenue offered a permissible delay by the retailer to customers, $0 \leq \rho \leq 1$

$\gamma$ The annual compound interest paid per dollar per year

$c$ The purchase cost per unit in dollars, $c>0$

$h$ The holding cost excluding interest charge per unit per year in dollars, $h>0$

$l$ The length of time in years during which the prepayments are paid, $l>0$

$I_{c}$ The interest charged by the supplier per dollar per year

$I_{e} \quad$ The interest earned per dollar per year

$m$ The time to the expiration date or the shelf life in years, $m>0$

$o$ The ordering cost in dollars per order, $o>0$

\subsubsection{Functions}

$\Sigma \quad$ The total purchase cost per cycle in dollars when placing an order at time $-l$

$\theta(t)$ The time-varying deterioration rate at time $t$

$I(t)$ The inventory level in units at time $t$

$Q \quad$ The order quantity in units

$C C$ The present value of capital cost per cycle in dollars

$H C$ The present value of holding cost excluding interest charge per cycle in dollars

$O C$ The present value of ordering cost per cycle in dollars

$P C$ The present value of purchase cost per cycle in dollars

$S R \quad$ The present value of sales revenue per cycle in dollars

$T P$ The present value of total annual profit in dollars

\subsubsection{Decision variables}

$P \quad$ The price per unit in dollars $(P>c>0)$

$T$ The length of cycle time in years $(T \leq m)$

For convenience, the asterisk symbol on a variable denotes the optimal solution of the variable. For instance, $P^{*}$ is the optimal solution of the unit price $P$. Next, the necessary assumptions to build an EOQ model for perishable goods with an ACC payment type are given below.

\subsection{Assumptions}

When the total purchase cost is high, the supplier (or the seller) usually demands an ACC payment in which the retailer (or the buyer) (1) prepays $\alpha$ percentage of total purchase cost $\Sigma$ (i.e., $\alpha \Sigma$ ) when placing an order at $l$ years prior to the time of delivery (i.e., $t=-l$ ), (2) pays 
another $\beta$ percentage of total purchase cost (i.e., $\beta \Sigma$ ) upon the receipt of all items at the time of delivery (i.e., $t=0$ ), and (3) receives an upstream credit period of $\mu$ years on the remaining $\chi$ portion of total purchase cost (i.e., $\chi \Sigma$, with $0 \leq \alpha, \beta, \chi \leq 1$, and $\alpha+\beta+\chi=1$ ). Notice that if the supplier does not request an advance payment, then $\alpha=0$. Similarly, if the supplier asks for an instant cash payment upon the receipt of the order quantity, then $\beta=1$. Furthermore, if the supplier offers a 50-50 partial trade credit, then $\beta=\chi=0.5$. Consequently, the ACC payment scheme includes 7 possible payment types.

Likewise, the retailer also offers customers a partial downstream trade credit, in which a customer is granted a credit period of $\delta$ years on $\rho$ fraction of sales and pays the remainder (i.e., $1-\rho$ fraction of sales) in cash. Notice that if $\rho=1$, then the retailer grants customers a full downstream credit period. If $\rho=0$, then customers must pay the entire sales amount in cash on delivery.

In economics, people will buy more of a product or service as its price falls. In addition, product freshness degenerates over time. Hence, today's health conscious consumers prefer a product further from its expiration date because it is fresher and can be stored longer. As a result, the demand for perishable goods is a function of unit price and stock age. By following Feng et al. (2017) and Li and Teng (2018), we assume that the demand is a multiplicative form of unit price and stock age as follows:

$$
D(t, P)=\frac{m-t}{m} f(P), \quad 0 \leq t \leq m,
$$

where $f(P)>0, f^{\prime}(P)<0$, and $f^{\prime \prime}(P) \geq 0$.

By following Chen and Teng (2015) and Chang et al. (2019), we assume the time-varying rate of deterioration $\theta(t)$ at time $t$ satisfies the following conditions:

$$
0 \leq \theta(t) \leq 1 \text {, and } \theta^{\prime}(t) \geq 0 .
$$

Most banks provide loans only based on good items as collateral, and do not provide loans based on deteriorated products as collateral. As a result, we derive the interest charged only based on good items (i.e., sold items) but not on deteriorated items.

Since the product cannot be sold after the expiration date, it is assumed that $\delta \leq m, \mu \leq$ $m$, and $T \leq m$.

There is no replacement, repair, financing, or salvage value of perished items during the replenishment cycle $[0, T]$.

\section{Mathematical model}

Given the above notation and assumptions, the proposed EOQ inventory model for perishable products is described as follows. The retailer pays the supplier $\alpha$ fraction of the total purchase $\operatorname{cost} \Sigma$ when placing an order at time $-l$ years. The order quantity (i.e., $Q$ units) arrives at time 0 . The quantity received is gradually depleted to zero at time $T$ due to the combination of demand and deterioration. Then the replenishment cycle repeats. Consequently, the inventory level at time $t$ is governed by the following differential equation:

$$
\frac{d I(t)}{d t}=-\left[\frac{m-t}{m} f(P)\right]-\theta(t) I(t), \quad 0 \leq t \leq T \leq m,
$$

with boundary condition $I(T)=0$. The solution of the above differential equation is:

$$
I(t)=e^{-\int_{0}^{t} \theta(u) d u} \int_{t}^{T}\left[\frac{m-t}{m} f(P)\right] e^{\int_{0}^{v} \theta(u) d u} d v, \quad 0 \leq t \leq T .
$$


From (3), it is clear that the order quantity delivered at time 0 is as follows:

$$
Q=I(0)=\int_{0}^{T}\left[\frac{m-t}{m} f(P)\right] e^{\int_{0}^{v} \theta(u) d u} d v=\int_{0}^{T} D(t, P) e^{\int_{0}^{v} \theta(u) d u} d v .
$$

The retailer's ordering time is $l$ years prior to the time of delivery 0 . Hence, the present value of ordering cost at time $-l$ is:

$$
O C=o e^{\gamma l}
$$

The retailer grants customers a partial downstream credit period $\delta$ (i.e., a customer receives items at time $t$, and must pay the credit payment at time $t+\delta$ ) on $\rho$ fraction of sales.

Hence, the retailer's present value of sales revenue per cycle time $T$ is as follows:

$$
S R=\rho P f(P) \int_{\delta}^{T+\delta} \frac{m-t+\delta}{m} e^{-\gamma t} d t+(1-\rho) P f(P) \int_{0}^{T} \frac{m-t}{m} e^{-\gamma t} d t .
$$

The total purchase cost without considering time value of money is given by:

$$
\Sigma=c Q=c f(P) \int_{0}^{T} \frac{m-t}{m} e^{\int_{0}^{t} \theta(u) d u} d t .
$$

The total purchase cost is divided into three payments as follows: (1) the advance payment at $l$ years before time $0,(2)$ the cash payment at time 0 , and (3) the credit payment at time $\mu$. Therefore, the present value of total purchase cost is given as:

$$
P C=\alpha \Sigma e^{\gamma l}+\beta \Sigma+\chi \Sigma e^{-\gamma \mu}=\Sigma\left(\alpha e^{\gamma l}+\beta+\chi e^{-\gamma \mu}\right) .
$$

The present value of the holding cost excluding interest charged per cycle time $T$ is described as follows:

$$
\begin{aligned}
H C & =h \int_{0}^{T} I(t) e^{-\gamma t} d t=h \int_{0}^{T} e^{-\int_{0}^{t} \theta(u) d u} \int_{t}^{T} D(t, P) e^{\int_{0}^{v} \theta(u) d u} d v e^{-\gamma t} d t \\
& =h f(P) \int_{0}^{T} \int_{t}^{T} \frac{m-t}{m} e^{\int_{t}^{v} \theta(u) d u-\gamma t} d v d t .
\end{aligned}
$$

The present value of interest charged for both advance and cash payments per cycle as shown in Figs. 1, 2 and 3 is given below:

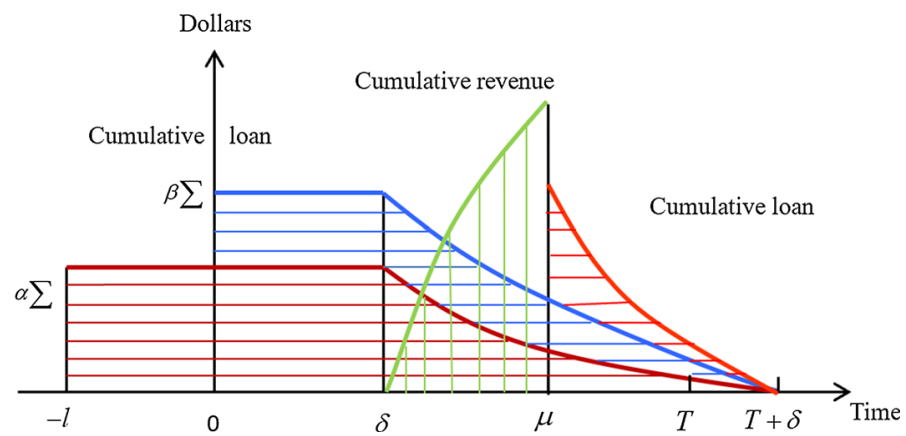

Fig. 1 The graphical representation of the case of $\delta \leq \mu \leq T+\delta$ 


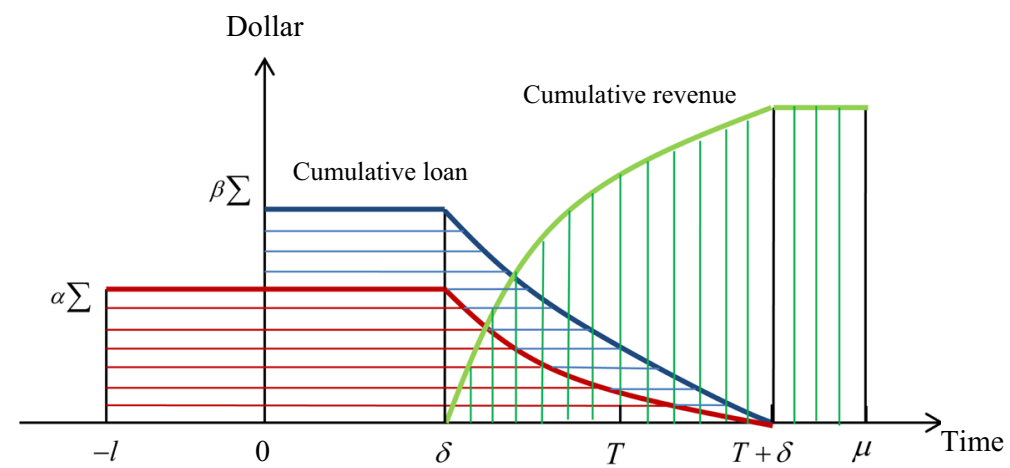

Fig. 2 The graphical representation of the case of $\delta<T+\delta \leq \mu$

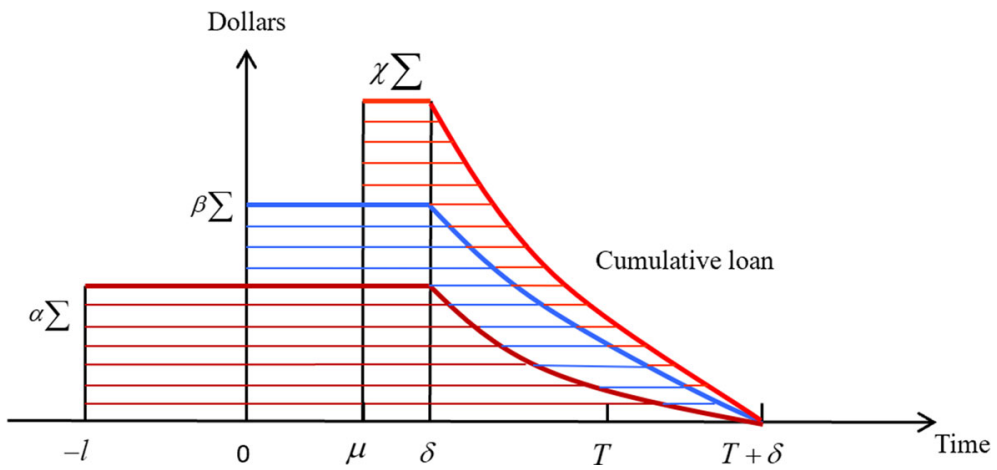

Fig. 3 The graphical representation of the case of $\delta \geq \mu$

$$
\begin{aligned}
I C_{\alpha \beta}= & I_{c} c f(P)\left(\alpha \int_{-l}^{\delta} e^{-\gamma t} d t+\beta \int_{0}^{\delta} e^{-\gamma t} d t\right) \int_{0}^{T} \frac{m-t}{m} e^{\int_{0}^{t} \theta(u) d u} d t \\
& +(\alpha+\beta) c I_{c} f(P) \int_{\delta}^{T+\delta} \frac{m-t+\delta}{m}(T+\delta-t) e^{-\gamma t} d t
\end{aligned}
$$

As to the credit payment, from the upstream credit period $\mu$ and the downstream credit period $\delta$, there are two potential cases: (i) $\delta \leq \mu$, and (ii) $\delta \geq \mu$. Let us discuss them separately.

\subsection{Case 1 of $\delta \leq \mu$}

Based on the downstream credit period $\mu$, and the timing $T+\delta$ at which the retailer receives the customer's last payment, there are two possible sub-cases.

\subsubsection{Sub-case 1 of $\delta \leq \mu$ and $\mu \leq T+\delta$}

In this sub-case, the present value of interest charged for credit payment per cycle time $T$ as shown in Fig. 1 is given by: 


$$
I C_{\chi}=\chi c I_{C} f(P)\left[\rho \int_{\mu}^{T+\delta} \frac{m-t+\delta}{m}(T+\delta-t) e^{-\gamma t} d t+(1-\rho) \int_{\mu}^{T} \frac{m-t}{m}(T-t) e^{-\gamma t} d t\right] .
$$

The present value of interest earned for credit payment per cycle time $T$ as depicted in Fig. 1 is as follows:

$$
I E_{\chi}=\chi P I_{e} f(P)\left[\rho \int_{\delta}^{\mu} \frac{m-t+\delta}{m}(t-\delta) e^{-\gamma t} d t+(1-\rho) \int_{0}^{\mu} \frac{m-t}{m} t e^{-\gamma t} d t\right] .
$$

From (10)-(12), we obtain the present value of capital cost per cycle time $T$ as follows:

$$
C C_{1}=I C_{\alpha \beta}+I C_{\chi}-I E_{\chi} .
$$

Combining (5)-(9) and (13), the present value of total annual profit is given by:

$$
\begin{aligned}
T P_{1}(P, T)= & \frac{1}{T}\left(S R-O C-P C-H C-C C_{1}\right) \\
= & \frac{1}{T}\left\{\rho P f(P) \int_{\delta}^{T+\delta} \frac{m-t+\delta}{m} e^{-\gamma t} d t+(1-\rho) P f(P) \int_{0}^{T} \frac{m-t}{m} e^{-\gamma t} d t\right. \\
& -o e^{\gamma l}-\left(\alpha e^{\gamma l}+\beta+\chi e^{-\gamma \mu}\right) c f(P) \int_{0}^{T} \frac{m-t}{m} e^{\int_{0}^{t} \theta(u) d u} d t \\
& -h f(P) \int_{0}^{T} \int_{t}^{T} \frac{m-t}{m} e^{\int_{t}^{v} \theta(u) d u-\gamma t} d v d t \\
& -c I_{c} f(P)\left[\alpha \int_{-l}^{\delta} e^{-\gamma t} d t+\beta \int_{0}^{\delta} e^{-\gamma t} d t\right] \int_{0}^{T} \frac{m-t}{m} e^{\int_{0}^{t} \theta(u) d u} d t \\
& -(\alpha+\beta) c I_{C} f(P) \int_{\delta}^{T+\delta} \frac{m-t+\delta}{m}(T+\delta-t) e^{-\gamma t} d t \\
& -\chi c I_{c} f(P)\left[\rho \int_{\mu}^{T+\delta} \frac{m-t+\delta}{m}(T+\delta-t) e^{-\gamma t} d t+(1-\rho) \int_{\mu}^{T} \frac{m-t}{m}(T-t) e^{-\gamma t} d t\right] \\
& \left.+\chi P I_{e} f(P)\left[\rho \int_{\delta}^{\mu} \frac{m-t+\delta}{m}(t-\delta) e^{-\gamma t} d t+(1-\rho) \int_{0}^{\mu} \frac{m-t}{m} t e^{-\gamma t} d t\right]\right\} .
\end{aligned}
$$

Now, the other sub-case in which $\delta \leq \mu$ and $\mu \geq T+\delta$ is discussed.

\subsubsection{Sub-case 2 of $\delta \leq \mu$ and $\mu \geq T+\delta$}

In this sub-case, the retailer receives all revenue at time $T+\delta$, and is able to pay the supplier the total purchase cost at time $\mu$ as described in Fig. 2. Hence, there is no interest charge for credit payment. Note that the cumulative sales volume per cycle time $T$ is

$$
\int_{0}^{T} D(t, P) d t=\int_{0}^{T} \frac{m-t}{m} f(P) d t=f(P)\left(T-\frac{T^{2}}{2 m}\right) .
$$

Hence, the present value of interest earned for credit payment per cycle time $T$ is given as:

$$
\begin{aligned}
I E_{\chi}= & \rho \chi P I_{e} f(P)\left[\int_{\delta}^{T+\delta} \frac{m-t+\delta}{m}(T+\delta-t) e^{-\gamma t} d t+\left(T-\frac{T^{2}}{2 m}\right) \int_{T+\delta}^{\mu} e^{-\gamma t} d t\right] \\
& +(1-\rho) \chi P I_{e} f(P)\left[\int_{0}^{T} \frac{m-t}{m}(T-t) e^{-\gamma t} d t+\left(T-\frac{T^{2}}{2 m}\right) \int_{T}^{\mu} e^{-\gamma t} d t\right] .
\end{aligned}
$$


Hence, the present value of capital cost per cycle time $T$ is as follows:

$$
C C_{2}=I C_{\alpha \beta}-I E_{\chi} .
$$

As a result, the present value of total annual profit is obtained as:

$$
\begin{aligned}
T P_{2}(P, T)= & \frac{1}{T}\left(S R-O C-P C-H C-C C_{2}\right) \\
= & \frac{1}{T}\left\{\rho P f(P) \int_{\delta}^{T+\delta} \frac{m-t+\delta}{m} e^{-\gamma t} d t+(1-\rho) P f(P) \int_{0}^{T} \frac{m-t}{m} e^{-\gamma t} d t\right. \\
& -o e^{\gamma l}-\left(\alpha e^{\gamma l}+\beta+\chi e^{-\gamma \mu}\right) c f(P) \int_{0}^{T} \frac{m-t}{m} e^{\int_{0}^{t} \theta(u) d u} d t \\
& -h f(P) \int_{0}^{T} \int_{t}^{T} \frac{m-t}{m} e^{\int_{t}^{v} \theta(u) d u-\gamma t} d v d t \\
& -c I_{c} f(P)\left(\alpha \int_{-l}^{\delta} e^{-\gamma t} d t+\beta \int_{0}^{\delta} e^{-\gamma t} d t\right) \int_{0}^{T} \frac{m-t}{m} e^{\int_{0}^{t} \theta(u) d u} d t \\
& -(\alpha+\beta) c I_{c} f(P) \int_{\delta}^{T+\delta} \frac{m-t+\delta}{m}(T+\delta-t) e^{-\gamma t} d t \\
& +\rho \chi P I_{e} f(P)\left[\int_{\delta}^{T+\delta} \frac{m-t+\delta}{m}(T+\delta-t) e^{-\gamma t} d t+\left(T-\frac{T^{2}}{2 m}\right) \int_{T+\delta}^{\mu} e^{-\gamma t} d t\right] \\
& \left.+(1-\rho) \chi P I_{e} f(P)\left[\int_{0}^{T} \frac{m-t}{m}(T-t) e^{-\gamma t} d t+\left(T-\frac{T^{2}}{2 m}\right) \int_{T}^{\mu} e^{-\gamma t} d t\right]\right\}
\end{aligned}
$$

Then the case in which $\delta \geq \mu$ is investigated.

\subsection{Case 2 of $\delta \geq \mu$}

In this case, there is no interest earned for credit payment as shown in Fig. 3. The present value of interest charged for credit payment per cycle time $T$ is derived as:

$$
\begin{aligned}
I C_{\chi}= & \chi c I_{c} f(P)\left\{\rho\left[\left(T-\frac{T^{2}}{2 m}\right) \int_{\mu}^{\delta} e^{-\gamma t} d t+\int_{\delta}^{T+\delta}\left(\frac{m-t+\delta}{m}\right)(T+\delta-t) e^{-\gamma t} d t\right]\right. \\
& \left.+(1-\rho) \int_{\mu}^{T}\left(\frac{m-t}{m}\right)(T-t) e^{-\gamma t} d t\right\} .
\end{aligned}
$$

Thus, the present value of capital cost per cycle time $T$ is given by:

$$
C C_{3}=I C_{\alpha \beta}+I C_{\chi} .
$$

Hence, the present value of total annual profit is as follows:

$$
\begin{aligned}
T P_{3}(P, T)= & \frac{1}{T}\left(S R-O C-P C-H C-C C_{3}\right) \\
= & \frac{1}{T}\left\{\rho P f(P) \int_{\delta}^{T+\delta} \frac{m-t+\delta}{m} e^{-\gamma t} d t+(1-\rho) P f(P) \int_{0}^{T} \frac{m-t}{m} e^{-\gamma t} d t\right. \\
& -o e^{\gamma l}-\left(\alpha e^{\gamma l}+\beta+\chi e^{-\gamma \mu}\right) c f(P) \int_{0}^{T} \frac{m-t}{m} e^{\int_{0}^{t} \theta(u) d u} d t
\end{aligned}
$$




$$
\begin{aligned}
& -h f(P) \int_{0}^{T} \int_{t}^{T} \frac{m-t}{m} e^{\int_{t}^{v} \theta(u) d u-\gamma t} d v d t \\
& -c I_{c} f(P)\left(\alpha \int_{-l}^{\delta} e^{-\gamma t} d t+\beta \int_{0}^{\delta} e^{-\gamma t} d t\right) \int_{0}^{T} \frac{m-t}{m} e^{\int_{0}^{t} \theta(u) d u} d t \\
& -(\alpha+\beta) c I_{c} f(P) \int_{\delta}^{T+\delta} \frac{m-t+\delta}{m}(T+\delta-t) e^{-\gamma t} d t \\
& -\chi c I_{c} f(P)\left\{\rho\left[\left(T-\frac{T^{2}}{2 m}\right) \int_{\mu}^{\delta} e^{-\gamma t} d t+\int_{\delta}^{T+\delta}\left(\frac{m-t+\delta}{m}\right)(T+\delta-t) e^{-\gamma t} d t\right]\right. \\
& \left.\left.+(1-\rho) \int_{\mu}^{T}\left(\frac{m-t}{m}\right)(T-t) e^{-\gamma t} d t\right\}\right\}
\end{aligned}
$$

Now, theoretical results and an optimal solution are derived in next section.

\section{Theoretical results}

Similar to Sect. 3, we study the case of $\delta \leq \mu$ first, and then the other case of $\delta \geq \mu$. It seems not to be tractable to prove that the present value of total annual profit is joint concave in $P$ and $T$ due to the complexity of the problem. However, it is possible to demonstrate that the present value of total annual profit is strictly pseudo-concave in $T$ if $P$ is given and is strictly concave in $P$ if $T$ is fixed. In addition, the graphs of $T P_{i}(P, T), i=1,2$, and 3 , as shown in Figs. 4, 5 and 6 below, indicate that $T P_{i}(P, T), i=1,2$, and 3 are joint concave in both $P$ and $T$.

\subsection{Case 1 of $\delta \leq \mu$}

Applying fraction concave theory in Cambini and Martein (2009, p. 245), the following results are obtained:

Theorem 1 For any give $P$, if the sales revenue is significantly larger than the purchase cost, then we obtain as follows:

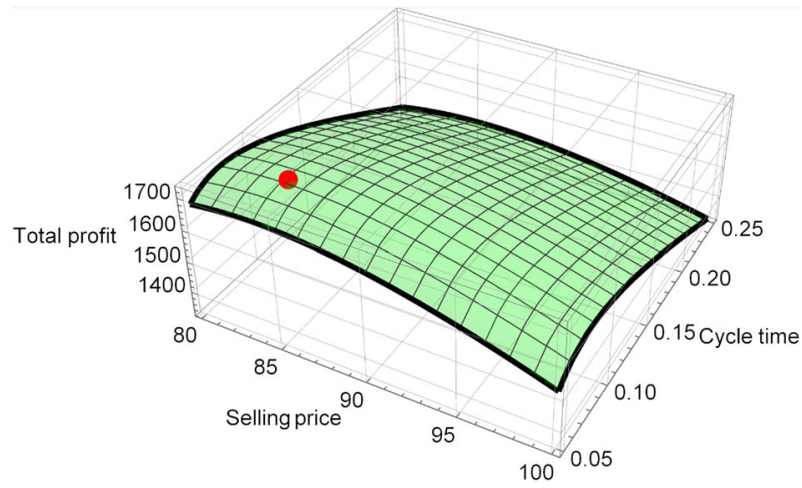

Fig. 4 The graph of $T P_{1}(P, T)$ 


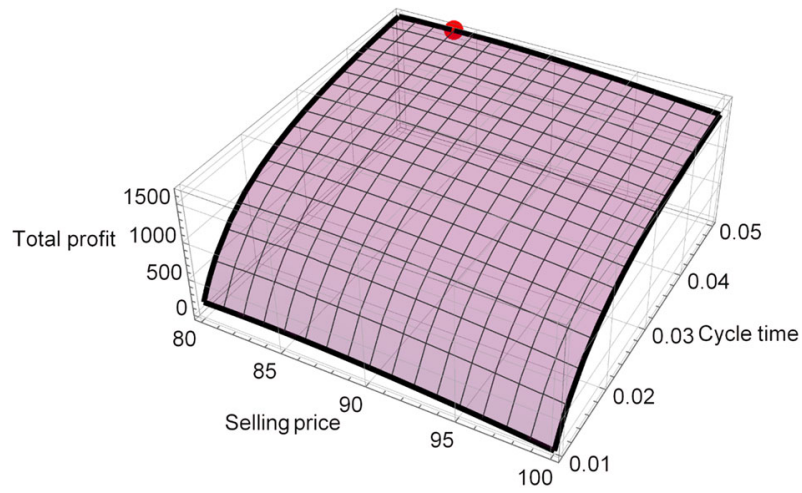

Fig. 5 The graph of $T P_{2}(P, T)$

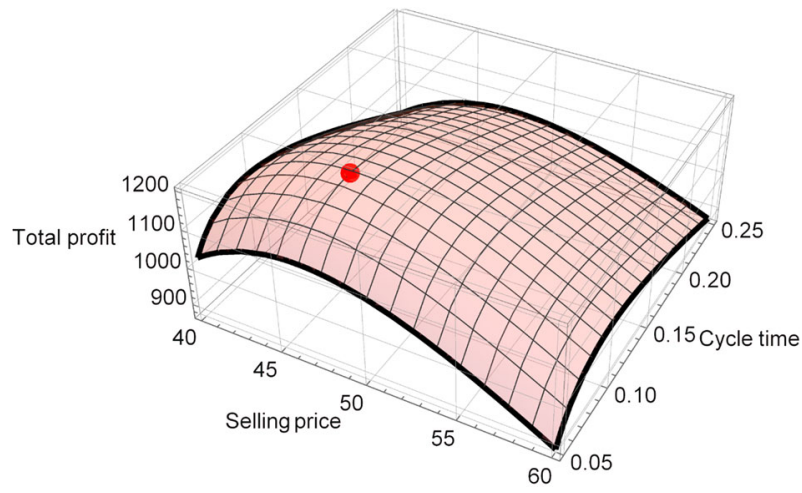

Fig. 6 The graph of $T P_{3}(P, T)$

(i) $T P_{1}(P, T)$ in (14) is a strictly pseudo-concave function of $T$, and hence there exists a unique maximum solution $T_{1}$.

(ii) $T P_{2}(P, T)$ in (18) is a strictly pseudo-concave function of $T$, and hence there exists a unique maximum solution $T_{2}$.

Proof See Appendix 1.

For any given price $P$, applying Theorem 1, taking the first-order derivative of $T P_{1}(P, T)$ with respect to $T$, setting the result to zero, and re-arranging terms, the necessary and sufficient condition for the unique replenishment cycle time $T_{1}$ is determined as follows:

$$
\begin{aligned}
& \rho P f(P)\left(\frac{m T-T^{2}}{m} e^{-\gamma(T+\delta)}-\int_{\delta}^{T+\delta} \frac{m-t+\delta}{m} e^{-\gamma t} d t\right) \\
& +(1-\rho) P f(P)\left(\frac{m T-T^{2}}{m} e^{-\gamma T}-\int_{0}^{T} \frac{m-t}{m} e^{-\gamma t} d t\right)+o e^{\gamma l} \\
& -\left(\alpha e^{\gamma l}+\beta+\chi e^{-\gamma \mu}\right) c f(P)\left(\frac{m T-T^{2}}{m} e^{\int_{0}^{T} \theta(u) d u}-\int_{0}^{T} \frac{m-t}{m} e^{\int_{0}^{t} \theta(u) d u} d t\right)
\end{aligned}
$$




$$
\begin{aligned}
& -h f(P)\left(T \int_{0}^{T} \frac{m-t}{m} e^{\int_{t}^{T} \theta(u) d u-\gamma t} d t-\int_{0}^{T} \int_{t}^{T} \frac{m-t}{m} e^{\int_{t}^{v} \theta(u) d u-\gamma t} d v d t\right) \\
& -c I_{c} f(P)\left(\alpha \int_{-l}^{\delta} e^{-\gamma t} d t+\beta \int_{0}^{\delta} e^{-\gamma t} d t\right)\left(\frac{m T-T^{2}}{m} e^{\int_{0}^{T} \theta(u) d u}-\int_{0}^{T} \frac{m-t}{m} e^{\int_{0}^{t} \theta(u) d u} d t\right) \\
& -(\alpha+\beta) c I_{c} f(P) \int_{\delta}^{T+\delta} \frac{m-t+\delta}{m}(t-\delta) e^{-\gamma t} d t \\
& -\chi c I_{c} f(P)\left[\rho \int_{\mu}^{T+\delta} \frac{m-t+\delta}{m}(t-\delta) e^{-\gamma t} d t+(1-\rho) \int_{\mu}^{T} \frac{m-t}{m} t e^{-\gamma t} d t\right] \\
& -\chi P I_{e} f(P)\left[\rho \int_{\delta}^{\mu} \frac{m-t+\delta}{m}(t-\delta) e^{-\gamma t} d t+(1-\rho) \int_{0}^{\mu} \frac{m-t}{m} t e^{-\gamma t} d t\right]=0 .
\end{aligned}
$$

Since $\mu-\delta \leq T_{1} \leq m$, it is clear from Theorem 1 that $T_{1}^{*}=T_{1}$, if $\mu-\delta \leq T_{1} \leq m$. If $T_{1} \geq m$, then $T_{1}^{*}=m$. If $T_{1} \leq \mu-\delta$, then $T_{1}^{*}=\mu-\delta$.

Likewise, the necessary and sufficient condition for the unique replenishment cycle time $T_{2}$ is obtained as follows:

$$
\begin{aligned}
& \rho P f(P)\left(\frac{m T-T^{2}}{m} e^{-\gamma(T+\delta)}-\int_{\delta}^{T+\delta} \frac{m-t+\delta}{m} e^{-\gamma t} d t\right) \\
& +(1-\rho) P f(P)\left(\frac{m T-T^{2}}{m} e^{-\gamma T}-\int_{0}^{T} \frac{m-t}{m} e^{-\gamma t} d t\right)+o e^{\gamma l} \\
& -\left(\alpha e^{\gamma l}+\beta+\chi e^{-\gamma \mu}\right) c f(P)\left(\frac{m T-T^{2}}{m} e^{\int_{0}^{T} \theta(u) d u}-\int_{0}^{T} \frac{m-t}{m} e^{\int_{0}^{t} \theta(u) d u} d t\right) \\
& -h f(P)\left(T \int_{0}^{T} \frac{m-t}{m} e^{\int_{t}^{T} \theta(u) d u-\gamma t} d t-\int_{0}^{T} \int_{t}^{T} \frac{m-t}{m} e^{\int_{t}^{v} \theta(u) d u-\gamma t} d v d t\right) \\
& -c I_{c} f(P)\left(\alpha \int_{-l}^{\delta} e^{-\gamma t} d t+\beta \int_{0}^{\delta} e^{-\gamma t} d t\right)\left(\frac{m T-T^{2}}{m} e^{\int_{0}^{T} \theta(u) d u}-\int_{0}^{T} \frac{m-t}{m} e^{\int_{0}^{t} \theta(u) d u} d t\right) \\
& -(\alpha+\beta) c I_{c} f(P) \int_{\delta}^{T+\delta} \frac{m-t+\delta}{m}(t-\delta) e^{-\gamma t} d t \\
& +\rho \chi P I_{e} f(P)\left[\int_{\delta}^{T+\delta} \frac{m-t+\delta}{m}(t-\delta) e^{-\gamma t} d t-\frac{T^{2}}{2 m} \int_{T+\delta}^{\mu} e^{-\gamma t} d t-\left(T^{2}-\frac{T^{3}}{2 m}\right) e^{-\gamma(T+\delta)}\right] \\
& +(1-\rho) \chi P I_{e} f(P)\left(\int_{0}^{T} \frac{m-t}{m} t e^{-\gamma t} d t-\frac{T^{2}}{2 m} \int_{T}^{\mu} e^{-\gamma t} d t-\left(T^{2}-\frac{T^{3}}{2 m}\right) e^{-\gamma T}\right)=0 .
\end{aligned}
$$

It is obvious from Theorem 1 and the fact of $T_{2} \leq \mu-\delta$ that $T_{2}^{*}=T_{2}$, if $T_{2} \leq \mu-\delta$. Otherwise, $T_{2}^{*}=\mu-\delta$.

Theorem 2 For any given cycle time $T$, if $2 f^{\prime}(P)+P f^{\prime \prime}(P)<0$, then

(i) $T P_{1}(P, T)$ in (14) is a strictly concave function of $P$, and hence there exists a unique maximum solution $P_{1}$.

(ii) $T P_{2}(P, T)$ in (18) is a strictly concave function of $P$, and hence there exists a unique maximum solution $P_{2}$.

Proof See Appendix 2. 
In reality, perishable goods must be consumed as soon as possible and cannot be used after its expiration date. As a result, the demand for perishable goods is relatively inelastic. As a result, the condition of $2 f^{\prime}(P)+P f^{\prime \prime}(P)<0$ is held for linear (i.e., $f(P)=a_{1}-$ $b_{1} P$, where $a_{1}, b_{1}>0$ ), constant elasticity (i.e., $f(P)=a_{2} P^{-b_{2}}$, where $a_{2}>0$, and $0<b_{2}<1$ ), and exponential (i.e., $f(P)=a_{3} e^{-b_{3} P}$, where $a_{3}>0$, and $b_{3} P<2$ ) demand curves.

For convenience, let

$$
\begin{aligned}
A_{1}= & \rho \int_{\delta}^{T+\delta} \frac{m-t+\delta}{m} e^{-\gamma t} d t+(1-\rho) \int_{0}^{T} \frac{m-t}{m} e^{-\gamma t} d t \\
& +\chi I_{e}\left[\rho \int_{\delta}^{\mu} \frac{m-t+\delta}{m}(t-\delta) e^{-\gamma t} d t+(1-\rho) \int_{0}^{\mu} \frac{m-t}{m} t e^{-\gamma t} d t\right]
\end{aligned}
$$

and

$$
\begin{aligned}
B_{1}= & \left(\alpha e^{\gamma l}+\beta+\chi e^{-\gamma \mu}\right) c \int_{0}^{T} \frac{m-t}{m} e^{\int_{0}^{t} \theta(u) d u} d t+h \int_{0}^{T} \int_{t}^{T} \frac{m-t}{m} e^{\int_{t}^{v} \theta(u) d u-\gamma t} d v d t \\
& +c I_{c}\left[\alpha \int_{-l}^{\delta} e^{-\gamma t} d t+\beta \int_{0}^{\delta} e^{-\gamma t} d t\right] \int_{0}^{T} \frac{m-t}{m} e^{\int_{0}^{t} \theta(u) d u} d t \\
& +(\alpha+\beta) c I_{c} \int_{\delta}^{T+\delta} \frac{m-t+\delta}{m}(T+\delta-t) e^{-\gamma t} d t \\
& +\chi c I_{c}\left[\rho \int_{\mu}^{T+\delta} \frac{m-t+\delta}{m}(T+\delta-t) e^{-\gamma t} d t+(1-\rho) \int_{\mu}^{T} \frac{m-t}{m}(T-t) e^{-\gamma t} d t\right] .
\end{aligned}
$$

For any given cycle time $T$, applying Theorem 2 and Eq. (38), we can derive the unique optimal price for the sub-case of $\delta \leq \mu$ and $\mu \leq T+\delta$ as follows:

$$
P_{1}^{*}=\frac{B_{1}}{A_{1}}-\frac{f(P)}{f^{\prime}(P)},
$$

Because $\left[f(P)+P f^{\prime}(P)\right] A_{1}-f^{\prime}(P) B_{1}=0$.

Similarly, for simplicity, let

$$
\begin{aligned}
A_{2}= & \rho \int_{\delta}^{T+\delta} \frac{m-t+\delta}{m} e^{-\gamma t} d t+(1-\rho) \int_{0}^{T} \frac{m-t}{m} e^{-\gamma t} d t \\
& +\chi I_{e} \rho\left[\int_{\delta}^{T+\delta} \frac{m-t+\delta}{m}(T+\delta-t) e^{-\gamma t} d t+\left(T-\frac{T^{2}}{2 m}\right) \int_{T+\delta}^{\mu} e^{-\gamma t} d t\right] \\
& +\chi I_{e}(1-\rho)\left[\int_{0}^{T} \frac{m-t}{m}(T-t) e^{-\gamma t} d t+\left(T-\frac{T^{2}}{2 m}\right) \int_{T}^{\mu} e^{-\gamma t} d t\right]
\end{aligned}
$$

and

$$
\begin{aligned}
B_{2}= & \left(\alpha e^{\gamma l}+\beta+\chi e^{-\gamma \mu}\right) c \int_{0}^{T} \frac{m-t}{m} e^{\int_{0}^{t} \theta(u) d u} d t \\
& +h \int_{0}^{T} \int_{t}^{T} \frac{m-t}{m} e^{\int_{t}^{v} \theta(u) d u-\gamma t} d v d t \\
& +c I_{c}\left[\alpha \int_{-l}^{\delta} e^{-\gamma t} d t+\beta \int_{0}^{\delta} e^{-\gamma t} d t\right] \int_{0}^{T} \frac{m-t}{m} e^{\int_{0}^{t} \theta(u) d u} d t
\end{aligned}
$$




$$
+(\alpha+\beta) c I_{c} \int_{\delta}^{T+\delta} \frac{m-t+\delta}{m}(T+\delta-t) e^{-\gamma t} d t .
$$

The unique optimal price for the sub-case of $\delta \leq \mu$ and $\mu \geq T+\delta$ is given as follows:

$$
P_{2}^{*}=\frac{B_{2}}{A_{2}}-\frac{f(P)}{f^{\prime}(P)} \text {. }
$$

\subsection{Case $2 \delta \geq \mu$}

Applying the same analogous argument as in Case 1, the following results are obtained.

Theorem 3 For any given unit price $P$, if the sales revenue is significantly larger than the purchase cost, then $T P_{3}(P, T)$ in (21) is a strictly pseudo concave function of $T$, and hence there exists a unique maximum solution $T_{3}$.

Proof See Appendix 3.

For any given price $P$, applying Theorem 3, taking the first-order derivative of $T P_{3}(P, T)$ with respect to $T$, setting the result to zero, and simplifying terms, the necessary and sufficient condition for the optimal replenishment cycle time $T_{3}$ is given by:

$$
\begin{aligned}
& \rho P f(P)\left(\frac{m T-T^{2}}{m} e^{-\gamma(T+\delta)}-\int_{\delta}^{T+\delta} \frac{m-t+\delta}{m} e^{-\gamma t} d t\right) \\
& +(1-\rho) P f(P)\left(\frac{m T-T^{2}}{m} e^{-\gamma T}-\int_{0}^{T} \frac{m-t}{m} e^{-\gamma t} d t\right)+o e^{\gamma l} \\
& -\left(\alpha e^{\gamma l}+\beta+\chi e^{-\gamma \mu}\right) c f(P)\left(\frac{m T-T^{2}}{m} e^{\int_{0}^{T} \theta(u) d u}-\int_{0}^{T} \frac{m-t}{m} e^{\int_{0}^{t} \theta(u) d u} d t\right) \\
& -h f(P)\left(T \int_{0}^{T} \frac{m-t}{m} e^{\int_{t}^{T} \theta(u) d u-\gamma t} d t-\int_{0}^{T} \int_{t}^{T} \frac{m-t}{m} e^{\int_{t}^{v} \theta(u) d u-\gamma t} d v d t\right) \\
& -c I_{c} f(P)\left(\alpha \int_{-l}^{\delta} e^{-\gamma t} d t+\beta \int_{0}^{\delta} e^{-\gamma t} d t\right)\left(\frac{m T-T^{2}}{m} e^{\int_{0}^{T} \theta(u) d u}-\int_{0}^{T} \frac{m-t}{m} e^{\int_{0}^{t} \theta(u) d u} d t\right) \\
& -(\alpha+\beta) c I_{c} f(P) \int_{\delta}^{T+\delta} \frac{m-t+\delta}{m}(t-\delta) e^{-\gamma t} d t \\
& -\chi c I_{c} f(P)\left\{\rho\left[\frac{-T^{2}}{2 m} \int_{\mu}^{\delta} e^{-\gamma t} d t+\int_{\delta}^{T+\delta}\left(\frac{m-t+\delta}{m}\right)(t-\delta) e^{-\gamma t} d t\right]\right. \\
& \left.+(1-\rho) \int_{\mu}^{T}\left(\frac{m-t}{m}\right) t e^{-\gamma t} d t\right\}=0 .
\end{aligned}
$$

Using the fact that $0<T_{3} \leq m$, and applying Theorem 3, we know that $T_{3}^{*}=T_{3}$, if $T_{3} \leq m$. Otherwise, $T_{3}^{*}=m$.

Theorem 4 For any given replenishment cycle time $T$, if $2 f^{\prime}(P)+P f^{\prime \prime}(P)<0$, then $T P_{3}(P, T)$ in (21) is a strictly concave function of $P$, and hence there exists a unique maximum solution $P_{1}$.

Proof See Appendix 4. 
Again, for simplicity, let

$$
A_{3}=\rho \int_{\delta}^{T+\delta} \frac{m-t+\delta}{m} e^{-\gamma t} d t+(1-\rho) \int_{0}^{T} \frac{m-t}{m} e^{-\gamma t} d t,
$$

and

$$
\begin{aligned}
B_{3}= & \left(\alpha e^{\gamma l}+\beta+\chi e^{-\gamma \mu}\right) c \int_{0}^{T} \frac{m-t}{m} e^{\int_{0}^{t} \theta(u) d u} d t+h \int_{0}^{T} \int_{t}^{T} \frac{m-t}{m} e^{\int_{t}^{v} \theta(u) d u-\gamma t} d v d t \\
& +c I_{c}\left[\alpha \int_{-l}^{\delta} e^{-\gamma t} d t+\beta \int_{0}^{\delta} e^{-\gamma t} d t\right] \int_{0}^{T} \frac{m-t}{m} e^{\int_{0}^{t} \theta(u) d u} d t \\
& +(\alpha+\beta) c I_{c} \int_{\delta}^{T+\delta} \frac{m-t+\delta}{m}(T+\delta-t) e^{-\gamma t} d t \\
& +\chi c I_{c}\left\{\rho\left[\left(T-\frac{T^{2}}{2 m}\right) \int_{\mu}^{\delta} e^{-\gamma t} d t+\int_{\delta}^{T+\delta}\left(\frac{m-t+\delta}{m}\right)(T+\delta-t) e^{-\gamma t} d t\right]\right. \\
& \left.+(1-\rho) \int_{\mu}^{T}\left(\frac{m-t}{m}\right)(T-t) e^{-\gamma t} d t\right\} .
\end{aligned}
$$

The unique optimal price for the sub-case of $\delta \leq \mu$ and $\mu \geq T+\delta$ is given by:

$$
P_{3}^{*}=\frac{B_{3}}{A_{3}}-\frac{f(P)}{f^{\prime}(P)} .
$$

Corollary An increase in fraction of advance payment $\alpha$, fraction of cash payment $\beta$, unit cost $c$, unit holding cost $h$, or interest charged $I_{c}$ elevates selling price $P^{*}$.

Proof It immediately follows from (24)-(29) and (31)-(33).

In the next section, several numerical examples are provided, and a sensitivity analysis is performed in order to illustrate the results and gain managerial insights.

\section{Numerical examples}

To illustrate two potential cases: $\delta \leq \mu$ and $\delta \geq \mu$, we provide the numerical example for the case of $\delta \leq \mu$ first, and then for the other case of $\delta \geq \mu$. Then, to gain an understanding as to whether the optimal solution is sensitive to changes in input parameters, the sensitivity analysis is conducted.

Example 1 For a perishable product, annual demand rate is $D(P)=2000 e^{-0.03 P}$, and deteriorating rate is $\theta(t)=0.02$. The parameter values are: $\alpha=0.2, \beta=0.2, \chi=0.6, \rho=0.4$, annual compounded interest rate $\gamma=0.04$ per dollar, downstream credit period $\delta=0.25$ years, upstream credit period $\mu=0.3$ years, unit cost $c=\$ 20$, holding cost $h=\$ 5$ per unit per year, prepayment time $l=0.1$ years, maximum lifetime $m=0.5$ years, ordering cost $o$ $=\$ 20$ per order, interest rate charged $I_{c}=0.05$ per dollar per year, and interest rate earned $I_{e}=0.04$ per dollar per year.

Solving (22), (23), (26) and (29), the optimal solutions to $T P_{1}(P, T)$ in (14) and $T P_{2}(P, T)$ in (18) are obtained respectively as follows:

$P_{1}=\$ 83.94, T_{1}=0.0780$ years, and $T P_{1}(P, T)=\$ 1,729.32$.

$P_{2}=\$ 83.71, T_{2}=0.0500$ years, and $T P_{2}(P, T)=\$ 1,654.41$. 
As a result, the optimal solution to the problem is

$$
P^{*}=\$ 83.94, T^{*}=0.0780 \text { years, and } T P^{*}(P, T)=\$ 1,729.32 \text {. }
$$

Note that $2 f^{\prime}(P)+P f^{\prime \prime}(P)=\left[-0.06+83.94(0.03)^{2}\right] f(P)=0.015546 f(P)>0$. Therefore, Theorem 2 cannot be applied to show that $T P_{1}(P, T)$ is strictly concave. However, the Hessian Matrix of $T P_{1}(P, T)$ at $\left(P_{1}, T_{1}\right)$ is derived as follows:

$$
\left[\begin{array}{cc}
-1.78752 & 23.5902 \\
23.59020 & -67,654.6000
\end{array}\right] \text {. }
$$

This proves that $T P_{1}(P, T)$ is maximum at $\left(P_{1}, T_{1}\right)$. Furthermore, the graphs of $T P_{1}(P, T)$ in (14) and $T P_{2}(P, T)$ in (18) are given in Figs. 4 and 5, respectively. It is clear that Figs. 4 and 5 indicate both $T P_{1}(P, T)$ and $T P_{2}(P, T)$ are joint concave in both $P$ and $T$. Note that the red dot in Figs. 4, 5 and 6 is the location of the optimal solution.

Example 2 For the case of $\delta \geq \mu$, it is assumed that all parameters here are the same as those in Example 1 except annual demand rate is $D(P)=2000 e^{-0.05 P}$, unit cost $c=\$ 10$, downstream credit period $\delta=0.35$ years, and upstream credit period $\mu=0.25$ years.

Solving (30) and (33), the optimal solution to $T P_{3}(P, T)$ in (21) is determined as follows:

$$
P^{*}=\$ 46.25, T^{*}=0.0980 \text { years, and } T P^{*}(P, T)=\$ 1,202.35 \text {. }
$$

The Hessian matrix of $T P_{3}(P, T)$ at the critical point $\left(P^{*}, T^{*}\right)$ is derived as follows:

$$
\left[\begin{array}{cc}
-3.51652 & 25.128 \\
25.128 & -43,192.8
\end{array}\right] \text {. }
$$

This demonstrates that $T P_{3}(P, T)$ is maximum at the critical point $\left(P^{*}, T^{*}\right)$. Furthermore, the graphs of $T P_{3}(P, T)$ in (21) is depicted in Fig. 6, which indicates $T P_{3}(P, T)$ is joint concave in both $P$ and $T$.

Example 3 The data in Example 1 are used to perform a sensitivity analysis on the effect of a single parameter change to the optimal solution. The numerical observations are given in Table 2.

From Table 2, we obtain the following managerial insights for both academicians and practitioners:

(1) An increase in fraction of advance payment $\alpha$ raises both selling price $P^{*}$ and cycle time $T^{*}$, but reduces total profit $T P^{*}$.

(2) Conversely, an increase in fraction of credit payment $\chi$ decreases both selling price $P^{*}$ and cycle time $T^{*}$ while increasing total profit $T P^{*}$.

(3) Likewise, the higher the fraction of downstream credit payment $\rho$, the lower the values of $P^{*}$ and $T^{*}$, but the higher the total profit $T P^{*}$.

(4) An increase in compound interest rate $\gamma$ causes lower values of $T^{*}$ and $T P^{*}$ but a higher value of $P^{*}$.

(5) A higher value of downstream trade credit $\delta$ leads to a higher value of selling price $P^{*}$, but a lower value of total profit $T P^{*}$.

(6) On the other hand, a higher value of upstream trade credit $\mu$ creates a lower value of selling price $P^{*}$ but a higher value of total profit $T P^{*}$.

(7) The earlier the prepayment time $l$, the higher the price $P^{*}$ and as well as the cycle time $T^{*}$ while the lower the total profit $T P^{*}$.

(8) An increase in shelf life $m$ leads to a longer cycle time $T^{*}$ and a higher total profit $T P^{*}$. 
Table 2 Sensitivity analysis with respect to each parameter

\begin{tabular}{|c|c|c|c|}
\hline Parameter & $P^{*}$ & $T^{*}$ & $T P^{*}$ \\
\hline$\alpha=0.1, \beta=0.3$ & $\$ 83.90$ & 0.0779 & $\$ 1732.00$ \\
\hline$\alpha=0.2, \beta=0.2$ & $\$ 83.94$ & 0.0780 & $\$ 1729.32$ \\
\hline$\alpha=0.3, \beta=0.1$ & $\$ 83.99$ & 0.0781 & $\$ 1726.64$ \\
\hline$\chi=0.5, \beta=0.3$ & $\$ 84.19$ & 0.0797 & $\$ 1711.83$ \\
\hline$\chi=0.6, \beta=0.2$ & $\$ 83.94$ & 0.0780 & $\$ 1729.32$ \\
\hline$\chi=0.7, \beta=0.1$ & $\$ 83.70$ & 0.0763 & $\$ 1749.09$ \\
\hline$\rho=0.3$ & $\$ 101.06$ & 0.1149 & $\$ 682.05$ \\
\hline$\rho=0.4$ & $\$ 83.94$ & 0.0780 & $\$ 1729.32$ \\
\hline$\rho=0.6$ & $\$ 73.82$ & 0.0613 & $\$ 3091.04$ \\
\hline$\gamma=0.04$ & $\$ 83.94$ & 0.0780 & $\$ 1729.32$ \\
\hline$\gamma=0.06$ & $\$ 84.07$ & 0.0778 & $\$ 1709.70$ \\
\hline$\gamma=0.08$ & $\$ 84.20$ & 0.0777 & $\$ 1690.21$ \\
\hline$\delta=0.20$ & $\$ 83.83$ & 0.0841 & $\$ 1738.86$ \\
\hline$\delta=0.25$ & $\$ 83.94$ & 0.0780 & $\$ 1729.32$ \\
\hline$\delta=0.30$ & $\$ 84.14$ & 0.0786 & $\$ 1713.40$ \\
\hline$\mu=0.25$ & $\$ 84.17$ & 0.0804 & $\$ 1710.86$ \\
\hline$\mu=0.30$ & $\$ 83.94$ & 0.0780 & $\$ 1729.32$ \\
\hline$\mu=0.35$ & $\$ 83.83$ & 0.0841 & $\$ 1738.43$ \\
\hline$l=0.05$ & $\$ 83.90$ & 0.0779 & $\$ 1732.52$ \\
\hline$l=0.10$ & $\$ 83.94$ & 0.0780 & $\$ 1729.32$ \\
\hline$l=0.20$ & $\$ 84.04$ & 0.0783 & $\$ 1722.91$ \\
\hline$m=0.4$ & $\$ 83.95$ & 0.0727 & $\$ 1680.39$ \\
\hline$m=0.5$ & $\$ 83.94$ & 0.0780 & $\$ 1729.32$ \\
\hline$m=0.6$ & $\$ 83.96$ & 0.0826 & $\$ 1763.30$ \\
\hline
\end{tabular}

\section{Conclusion and future research}

People will buy more of a product or service as its price falls. Also, product freshness degenerates over time. Hence, today's health conscious consumers prefer a perishable product further from its expiration date because it is fresher and can be stored longer. As a result, the demand for perishable goods depends on both selling price and stock age. Furthermore, a seller usually demands an upfront down payment for an expensive business transaction to avoid order cancellations, and simultaneously offers a trade credit to stimulate sales. Hence, ACC payments is commonly used in business transactions. In this paper, we have developed an inventory model interfaced with finance, marketing, and operations in a three-echelon supplier-retailer-consumer chain which captures the following important and relevant facts: (1) the demand curve for a seasonal or perishable product is downward sloping of selling price and stock age, (2) the retailer receives an ACC payment from the supplier while granting a cash-credit payment to consumers, and (3) the deterioration rate of perishable goods is time-varying. Then we have derived the optimal selling price and replenishment cycle for the retailer to maximize total profit by using a discounted cash-flow analysis. Finally, we have performed a sensitivity analysis to gain managerial insights. For example, An increase in fraction of advance payment raises both selling price and cycle time, but reduces total profit. 
Conversely, an increase in fraction of credit payment has completely opposite results as an increase in fraction of advance payment.

The opportunities for future research are always plentiful. First of all, the deterioration rate of a perishable good depends on many factors such as temperature, weather, refrigeration, and location. Hence, how to explicitly quantify the deteriorating rate over time would be challenging and important for future research. Secondly, as the revenues from online sales continued to grow significantly especially amid the COVID-19 pandemic, today's companies sell their products through a dual-channel, which combines a traditional retail channel and a direct online channel. As a result, to capture a wide range of consumers, the proposed model should be extended from a single retail channel to a dual-channel as studied in Modak and Kelle (2019). Thirdly, in reality, product quality and advertising frequency are the other important decision variables to influence the demand rate. Hence, the demand pattern could be expanded as a dynamic function of the selling price, product quality, and advertising frequency. Fourthly, a large display of goods in a supermarket induces consumers to buy more due to its variety, visibility, and seasonality. So, the demand could be expanded to be stock-dependent as stipulated in Mishra et al. (2017) and Tiwari et al. (2017). Finally, the individual decision-making in supply chains results in suboptimal overall performance. To improve the performance for all of the participants in supply chains, the decentralized decision-making could be expanded to cooperative integrated coordination of their decisions as shown in Jaggi et al. (2019).

Acknowledgements The principal author's research was funded by the Chinese National Natural Science Fund with Grant No. 71573177. The corresponding author's research was supported by the Assigned Released Time for Research from William Paterson University of New Jersey and a research Grant from Chaoyang University of Technology in ROC.

\section{Appendix 1: Proof of Theorem 1}

From (14), we define

$$
\begin{aligned}
x_{1}(T)= & \rho P f(P) \int_{\delta}^{T+\delta} \frac{m-t+\delta}{m} e^{-\gamma t} d t+(1-\rho) P f(P) \int_{0}^{T} \frac{m-t}{m} e^{-\gamma t} d t \\
& -o e^{\gamma l}-\left(\alpha e^{\gamma l}+\beta+\chi e^{-\gamma \mu}\right) c f(P) \int_{0}^{T} \frac{m-t}{m} e^{\int_{0}^{t} \theta(u) d u} d t \\
& -h f(P) \int_{0}^{T} \int_{t}^{T} \frac{m-t}{m} e^{\int_{t}^{v} \theta(u) d u-\gamma t} d v d t \\
& -c I_{c} f(P)\left[\alpha \int_{-l}^{\delta} e^{-\gamma t} d t+\beta \int_{0}^{\delta} e^{-\gamma t} d t\right] \int_{0}^{T} \frac{m-t}{m} e^{\int_{0}^{t} \theta(u) d u} d t \\
& -(\alpha+\beta) c I_{c} f(P) \int_{\delta}^{T+\delta} \frac{m-t+\delta}{m}(T+\delta-t) e^{-\gamma t} d t \\
& -\chi c I_{c} f(P)\left[\rho \int_{\mu}^{T+\delta} \frac{m-t+\delta}{m}(T+\delta-t) e^{-\gamma t} d t+(1-\rho) \int_{\mu}^{T} \frac{m-t}{m}(T-t) e^{-\gamma t} d t\right] \\
& +\chi P I_{e} f(P)\left[\rho \int_{\delta}^{\mu} \frac{m-t+\delta}{m}(t-\delta) e^{-\gamma t} d t+(1-\rho) \int_{0}^{\mu} \frac{m-t}{m} t e^{-\gamma t} d t\right],
\end{aligned}
$$

and

$$
y_{1}(T)=T>0 .
$$


Therefore, $T P_{1}(P, T)=x_{1}(T) / y_{1}(T)$. Taking the first- and second-order derivatives of $x_{1}(T)$ with respect to $T$ respectively, and simplifying terms, we obtain as follows:

$$
\begin{aligned}
x_{1}^{\prime}(T)= & \frac{P f(P)(m-T)}{m}\left[\rho e^{-\gamma(T+\delta)}+(1-\rho) e^{-\gamma T}\right] \\
& -\left(\alpha e^{\gamma l}+\beta+\chi e^{-\gamma \mu}\right) c f(P) \frac{m-T}{m} e^{\int_{0}^{T} \theta(u) d u} \\
& -h f(P) \int_{0}^{T} \frac{m-t}{m} e^{\int_{t}^{T} \theta(u) d u-\gamma t} d t \\
& -c I_{c} f(P)\left[\alpha \int_{-l}^{\delta} e^{-\gamma t} d t+\beta \int_{0}^{\delta} e^{-\gamma t} d t\right] \frac{m-T}{m} e^{\int_{0}^{T} \theta(u) d u} \\
& -(\alpha+\beta) c I_{c} f(P) \int_{\delta}^{T+\delta} \frac{m-t+\delta}{m} e^{-\gamma t} d t \\
& -\chi c I_{c} f(P)\left[\rho \int_{\mu}^{T+\delta} \frac{m-t+\delta}{m} e^{-\gamma t} d t+(1-\rho) \int_{\mu}^{T} \frac{m-t}{m} e^{-\gamma t} d t\right],
\end{aligned}
$$

and

$$
\begin{aligned}
x_{1}^{\prime \prime}(T)= & -P f(P) \frac{1+\gamma(m-T)}{m}\left[\rho e^{-\gamma(T+\delta)}+(1-\rho) e^{-\gamma T}\right] \\
& -\left(\alpha e^{\gamma l}+\beta+\chi e^{-\gamma \mu}\right) c f(P) e^{\int_{0}^{T} \theta(u) d u}\left[\frac{\theta(T)(m-T)-1}{m}\right] \\
& -h f(P)\left[\frac{m-T}{m} e^{-\gamma T}+\int_{0}^{T} \frac{m-t}{m} \theta(T) e^{\int_{t}^{T} \theta(u) d u-\gamma t} d t\right] \\
& -c I_{c} f(P)\left[\alpha \int_{-l}^{\delta} e^{-\gamma t} d t+\beta \int_{0}^{\delta} e^{-\gamma t} d t\right] e^{\int_{0}^{T} \theta(u) d u\left[\frac{\theta(T)(m-T)-1}{m}\right]} \\
& \left.-(\alpha+\beta) c I_{c} f(P) \frac{m-T}{m} e^{-\gamma(T+\delta)}\right] \\
& -\chi c I_{c} f(P) \frac{m-T}{m}\left[\rho e^{-\gamma(T+\delta)}+(1-\rho) e^{-\gamma T}\right]<0 .
\end{aligned}
$$

In general, the sales revenue is significantly larger than the purchase cost. There are only two positive terms (i.e., the second and the fourth terms) in (37), which are related to the purchase cost. Hence, we may assume for the most part that $x_{1}^{\prime \prime}(T)<0$. By applying fraction concave theory in Cambini and Martein (2009, p. 245), we know that $T P_{1}(P, T)=$ $x_{1}(T) / y_{1}(T)$ is strictly pseudo-concave in $T$. Hence, there exists a unique global maximum $T_{1}$. This completes the proof of Part (i) of Theorem 1. By using an analogous argument, we can prove Part (ii) of Theorem 1.

\section{Appendix 2: Proof of Theorem 2}

For any given replenishment cycle time $T$, applying (14), define $T P_{1}(P) \equiv T P_{1}(P, T)$. Taking the first- and second-order derivatives of $T P_{1}(P)$ with respect to $P$ respectively, and simplifying terms, we get:

$$
T\left[T P_{1}^{\prime}(P)\right]=\left[f(P)+P f^{\prime}(P)\right]\left\{\rho \int_{\delta}^{T+\delta} \frac{m-t+\delta}{m} e^{-\gamma t} d t+(1-\rho) \int_{0}^{T} \frac{m-t}{m} e^{-\gamma t} d t\right.
$$




$$
\begin{aligned}
& \left.+\chi I_{e}\left[\rho \int_{\delta}^{\mu} \frac{m-t+\delta}{m}(t-\delta) e^{-\gamma t} d t+(1-\rho) \int_{0}^{\mu} \frac{m-t}{m} t e^{-\gamma t} d t\right]\right\} \\
& -f^{\prime}(P)\left\{\left(\alpha e^{\gamma l}+\beta+\chi e^{-\gamma \mu}\right) c \int_{0}^{T} \frac{m-t}{m} e^{\int_{0}^{t} \theta(u) d u} d t+h \int_{0}^{T} \int_{t}^{T} \frac{m-t}{m} e^{\int_{t}^{v} \theta(u) d u-\gamma t} d v d t\right. \\
& +c I_{c}\left[\alpha \int_{-l}^{\delta} e^{-\gamma t} d t+\beta \int_{0}^{\delta} e^{-\gamma t} d t\right] \int_{0}^{T} \frac{m-t}{m} e^{\int_{0}^{t} \theta(u) d u} d t \\
& +(\alpha+\beta) c I_{c} \int_{\delta}^{T+\delta} \frac{m-t+\delta}{m}(T+\delta-t) e^{-\gamma t} d t \\
& \left.+\chi c I_{c}\left[\rho \int_{\mu}^{T+\delta} \frac{m-t+\delta}{m}(T+\delta-t) e^{-\gamma t} d t+(1-\rho) \int_{\mu}^{T} \frac{m-t}{m}(T-t) e^{-\gamma t} d t\right]\right\}
\end{aligned}
$$

and

$$
\begin{aligned}
T\left[T P_{1}^{\prime \prime}(p)\right]= & {\left[2 f^{\prime}(P)+P f^{\prime \prime}(P)\right]\left\{\rho \int_{\delta}^{T+\delta} \frac{m-t+\delta}{m} e^{-\gamma t} d t+(1-\rho) \int_{0}^{T} \frac{m-t}{m} e^{-\gamma t} d t\right.} \\
& \left.+\chi I_{e}\left[\rho \int_{\delta}^{\mu} \frac{m-t+\delta}{m}(t-\delta) e^{-\gamma t} d t+(1-\rho) \int_{0}^{\mu} \frac{m-t}{m} t e^{-\gamma t} d t\right]\right\} \\
& -f^{\prime \prime}(P)\left\{\left(\alpha e^{\gamma l}+\beta+\chi e^{-\gamma \mu}\right) c \int_{0}^{T} \frac{m-t}{m} e^{\int_{0}^{t} \theta(u) d u} d t+h \int_{0}^{T} \int_{t}^{T} \frac{m-t}{m} e^{\int_{t}^{v} \theta(u) d u-\gamma t} d v d t\right. \\
& +c I_{c}\left[\alpha \int_{-l}^{\delta} e^{-\gamma t} d t+\beta \int_{0}^{\delta} e^{-\gamma t} d t\right] \int_{0}^{T} \frac{m-t}{m} e^{\int_{0}^{t} \theta(u) d u} d t \\
& +(\alpha+\beta) c I_{c} \int_{\delta}^{T+\delta} \frac{m-t+\delta}{m}(T+\delta-t) e^{-\gamma t} d t \\
& \left.+\chi c I_{c}\left[\rho \int_{\mu}^{T+\delta} \frac{m-t+\delta}{m}(T+\delta-t) e^{-\gamma t} d t+(1-\rho) \int_{\mu}^{T} \frac{m-t}{m}(T-t) e^{-\gamma t} d t\right]\right\} .
\end{aligned}
$$

It is clear from (39) that $T P_{1}^{\prime \prime}(P)<0$, if $2 f^{\prime}(P)+P f^{\prime \prime}(P)<0$. This completes the proof of Part (i) of Theorem 2. By using an analogous argument, we can verify Part (ii) of Theorem 2.

\section{Appendix 3: Proof of Theorem 3}

Using (21), we define

$$
\begin{aligned}
x_{3}(T)= & \rho P f(P) \int_{\delta}^{T+\delta} \frac{m-t+\delta}{m} e^{-\gamma t} d t+(1-\rho) P f(P) \int_{0}^{T} \frac{m-t}{m} e^{-\gamma t} d t \\
& -o e^{\gamma l}-\left(\alpha e^{\gamma l}+\beta+\chi e^{-\gamma \mu}\right) c f(P) \int_{0}^{T} \frac{m-t}{m} e^{\int_{0}^{t} \theta(u) d u} d t \\
& -h f(P) \int_{0}^{T} \int_{t}^{T} \frac{m-t}{m} e^{\int_{t}^{v} \theta(u) d u-\gamma t} d v d t \\
& -c I_{c} f(P)\left(\alpha \int_{-l}^{\delta} e^{-\gamma t} d t+\beta \int_{0}^{\delta} e^{-\gamma t} d t\right) \int_{0}^{T} \frac{m-t}{m} e^{\int_{0}^{t} \theta(u) d u} d t \\
& -(\alpha+\beta) c I_{c} f(P) \int_{\delta}^{T+\delta} \frac{m-t+\delta}{m}(T+\delta-t) e^{-\gamma t} d t \\
& -\chi c I_{c} f(P)\left\{\rho\left[\left(T-\frac{T^{2}}{2 m}\right) \int_{\mu}^{\delta} e^{-\gamma t} d t+\int_{\delta}^{T+\delta}\left(\frac{m-t+\delta}{m}\right)(T+\delta-t) e^{-\gamma t} d t\right]\right. \\
& \left.+(1-\rho) \int_{\mu}^{T}\left(\frac{m-t}{m}\right)(T-t) e^{-\gamma t} d t\right\} .
\end{aligned}
$$


and

$$
y_{3}(T)=T>0 .
$$

Hence, $T P_{3}(P, T)=x_{3}(T) / y_{3}(T)$. Taking the first- and second-order derivatives of $x_{3}(T)$ with respect to $T$ respectively, and simplifying terms, we get:

$$
\begin{aligned}
x_{3}^{\prime}(T)= & \frac{P f(P)(m-T)}{m}\left[\rho e^{-\gamma(T+\delta)}+(1-\rho) e^{-\gamma T}\right]-\left(\alpha e^{\gamma l}+\beta+\chi e^{-\gamma \mu}\right) c f(P) \frac{m-T}{m} e^{\int_{0}^{T} \theta(u) d u} \\
& -h f(P) \int_{0}^{T} \frac{m-t}{m} e^{\int_{t}^{T} \theta(u) d u-\gamma t} d t-c I_{c} f(P)\left[\alpha \int_{-l}^{\delta} e^{-\gamma t} d t+\beta \int_{0}^{\delta} e^{-\gamma t} d t\right] \frac{m-T}{m} e^{\int_{0}^{T} \theta(u) d u} \\
& -(\alpha+\beta) c I_{c} f(P) \int_{\delta}^{T+\delta} \frac{m-t+\delta}{m} e^{-\gamma t} d t \\
& -\chi c I_{c} f(P)\left\{\rho\left[\left(1-\frac{T}{m}\right) \int_{\mu}^{\delta} e^{-\gamma t} d t+\int_{\delta}^{T+\delta}\left(\frac{m-t+\delta}{m}\right) e^{-\gamma t} d t\right]\right. \\
& \left.+(1-\rho) \int_{\mu}^{T}\left(\frac{m-t}{m}\right) e^{-\gamma t} d t\right\} .
\end{aligned}
$$

and

$$
\begin{aligned}
x_{3}^{\prime \prime}(T)= & -P f(P) \frac{1+\gamma(m-T)}{m}\left[\rho e^{-\gamma(T+\delta)}+(1-\rho) e^{-\gamma T}\right] \\
& -\left(\alpha e^{\gamma l}+\beta+\chi e^{-\gamma \mu}\right) c f(P) e^{\int_{0}^{T} \theta(u) d u\left[\frac{\theta(T)(m-T)-1}{m}\right]} \\
& -h f(P)\left[\frac{m-T}{m} e^{-\gamma T}+\int_{0}^{T} \frac{m-t}{m} \theta(T) e^{\int_{t}^{T} \theta(u) d u-\gamma t} d t\right] \\
& -c I_{c} f(P)\left[\alpha \int_{-l}^{\delta} e^{-\gamma t} d t+\beta \int_{0}^{\delta} e^{-\gamma t} d t\right] e^{\int_{0}^{T} \theta(u) d u}\left[\frac{\theta(T)(m-T)-1}{m}\right] \\
& \left.-(\alpha+\beta) c I_{c} f(P) \frac{m-T}{m} e^{-\gamma(T+\delta)}\right] \\
& -\chi c I_{c} f(P)\left\{\rho\left[\frac{-1}{m} \int_{\mu}^{\delta} e^{-\gamma t} d t+\frac{m-T}{m} e^{-\gamma(T+\delta)}\right]+(1-\rho) \frac{m-T}{m} e^{-\gamma T}\right\}<0 .
\end{aligned}
$$

In general, the sales revenue is significantly larger than the purchase cost. There are only three positive terms in (43), which are related to the purchase cost. Hence, we may assume for the most part that $x_{1}^{\prime \prime}(T)<0$. By applying fraction concave theory in Cambini and Martein (2009, p. 245), we know that $T P_{3}(P, T)=x_{3}(T) / y_{3}(T)$ is strictly pseudo-concave in $T$. Hence, there exists a unique global maximum $T_{1}$. This completes the proof of Theorem 3 .

\section{Appendix 4: Proof of Theorem 4}

For any given cycle time $T$, using (21), we define $T P_{3}(P) \equiv T P_{3}(P, T)$. Taking the first- and second-order derivatives of $T P_{3}(P)$ with respect to $P$ respectively, and simplifying terms, we have:

$$
T\left[T P_{3}^{\prime}(P)\right]=\left[f(P)+P f^{\prime}(P)\right]\left[\rho \int_{\delta}^{T+\delta} \frac{m-t+\delta}{m} e^{-\gamma t} d t+(1-\rho) \int_{0}^{T} \frac{m-t}{m} e^{-\gamma t} d t\right]
$$




$$
\begin{aligned}
& -f^{\prime}(P)\left\{\left(\alpha e^{\gamma l}+\beta+\chi e^{-\gamma \mu}\right) c \int_{0}^{T} \frac{m-t}{m} e^{\int_{0}^{t} \theta(u) d u} d t+h \int_{0}^{T} \int_{t}^{T} \frac{m-t}{m} e^{\int_{t}^{v} \theta(u) d u-\gamma t} d v d t\right. \\
& +c I_{c}\left[\alpha \int_{-l}^{\delta} e^{-\gamma t} d t+\beta \int_{0}^{\delta} e^{-\gamma t} d t\right] \int_{0}^{T} \frac{m-t}{m} e^{\int_{0}^{t} \theta(u) d u} d t \\
& +(\alpha+\beta) c I_{c} \int_{\delta}^{T+\delta} \frac{m-t+\delta}{m}(T+\delta-t) e^{-\gamma t} d t \\
& +\chi c I_{c}\left\{\rho\left[\left(T-\frac{T^{2}}{2 m}\right) \int_{\mu}^{\delta} e^{-\gamma t} d t+\int_{\delta}^{T+\delta}\left(\frac{m-t+\delta}{m}\right)(T+\delta-t) e^{-\gamma t} d t\right]\right. \\
& \left.+(1-\rho) \int_{\mu}^{T}\left(\frac{m-t}{m}\right)(T-t) e^{-\gamma t} d t\right\}
\end{aligned}
$$

and

$$
\begin{aligned}
T\left[T P_{3}^{\prime \prime}(p)\right]= & {\left[2 f^{\prime}(P)+P f^{\prime \prime}(P)\right]\left[\rho \int_{\delta}^{T+\delta} \frac{m-t+\delta}{m} e^{-\gamma t} d t+(1-\rho) \int_{0}^{T} \frac{m-t}{m} e^{-\gamma t} d t\right] } \\
& -f^{\prime \prime}(P)\left\{\left(\alpha e^{\gamma l}+\beta+\chi e^{-\gamma \mu}\right) c \int_{0}^{T} \frac{m-t}{m} e^{\int_{0}^{t} \theta(u) d u} d t\right. \\
& +h \int_{0}^{T} \int_{t}^{T} \frac{m-t}{m} e^{\int_{t}^{v} \theta(u) d u-\gamma t} d v d t \\
& +c I_{c}\left[\alpha \int_{-l}^{\delta} e^{-\gamma t} d t+\beta \int_{0}^{\delta} e^{-\gamma t} d t\right] \int_{0}^{T} \frac{m-t}{m} e^{\int_{0}^{t} \theta(u) d u} d t \\
& +(\alpha+\beta) c I_{c} \int_{\delta}^{T+\delta} \frac{m-t+\delta}{m}(T+\delta-t) e^{-\gamma t} d t \\
& +\chi c I_{c}\left\{\rho\left[\left(T-\frac{T^{2}}{2 m}\right) \int_{\mu}^{\delta} e^{-\gamma t} d t+\int_{\delta}^{T+\delta}\left(\frac{m-t+\delta}{m}\right)(T+\delta-t) e^{-\gamma t} d t\right]\right. \\
& \left.+(1-\rho) \int_{\mu}^{T}\left(\frac{m-t}{m}\right)(T-t) e^{-\gamma t} d t\right\} .
\end{aligned}
$$

It is obvious from (45) that $T P_{3}^{\prime \prime}(P)<0$, if $2 f^{\prime}(P)+P f^{\prime \prime}(P)<0$. This completes the proof of Theorem 4 .

\section{References}

Bakker, M., Riezebos, J., \& Teunter, R. H. (2012). Review of inventory systems with deterioration since 2001. European Journal of Operational Research, 221(2), 275-284.

Cambini, A., \& Martein, L. (2009). Generalized convexity and optimization: Theory and application. Springer. Cárdenas-Barrón, L. E., Shaikh, A. A., Tiwari, S., \& Treviño-Garza, G. (2020). An EOQ inventory model with nonlinear stock dependent holding cost, nonlinear stock dependent demand and trade credit. Computers and Industrial Engineering, 139, 105557.

Chang, C. T., Ouyang, L. Y., Teng, J. T., Lai, K. K., \& Cárdenas-Barrón, L. E. (2019). Manufacturer's pricing and lot-sizing decisions for perishable goods under various payment terms by a discounted cash flow analysis. International Journal of Production Economics, 218(1-2), 83-95.

Chen, S. C., \& Teng, J. T. (2014). Retailer's optimal ordering policy for deteriorating items with maximum lifetime under supplier's trade credit financing. Applied Mathematical Modelling, 38(15-16), 4049-4061.

Chen, S. C., \& Teng, J. T. (2015). Inventory and credit decisions for time-varying deteriorating items with up-stream and down-stream trade credit financing by discounted cash-flow analysis. European Journal of Operational Research, 243(2), 566-575.

Chen, K., \& Xiao, T. (2017). Pricing and replenishment policies in a supply chain with competing retailers under different retail behaviors. Computers and Industrial Engineering, 103, 145-157. 
Chen, S. C., Min, J., Teng, J. T., \& Li, F. (2016). Inventory and shelf-space management for fresh produce with freshness-and-stock dependent demand and expiration date. Journal of the Operational Research Society, 67(6), 884-896.

Dye, C. Y., Yang, C. T., \& Kung, F. C. (2014). A note on: Seller's optimal credit period and cycle time in a supply chain for deteriorating items with maximum lifetime. European Journal of Operational Research, 239(3), 868-871.

Feng, L., \& Chan, Y. L. (2019). Joint pricing and production decisions for new products with learning curve effects under upstream and downstream trade credits. European Journal of Operational Research, 272(3), 905-913.

Feng, L., Chan, Y. L., \& Cárdenas-Barrón, L. E. (2017). Pricing and lot-sizing polices for perishable goods when the demand depends on selling price, displayed stocks, and expiration date. International Journal of Production Economics, 185(3), 11-20.

Feng, L., Skouri, K., Wang, W. C., \& Teng, J. T. (2020). Optimal selling price, replenishment cycle and payment time among advance, cash, and credit payments from the seller's perspective. Annals of Operations Research. https://doi.org/10.1007/s10479-020-03761-y

Gupta, M., Tiwari, S., \& Jaggi, C. K. (2020). Retailer's ordering policies for time-varying deteriorating items with partial backlogging and permissible delay in payments in a two-warehouse environment. Annals of Operations Research, 295, 139-161.

Harris, F. W. (1913). How many parts to make at once. Factory, The Magazine of Management, 10(2), 135-136 and 152 .

Jaggi, C. K., Gupta, M., Kausar, A., \& Tiwari, S. (2019). Inventory and credit decisions for deteriorating items with displayed stock dependent demand in two-echelon supply chain using Stackelberg and Nash equilibrium solution. Annals of Operations Research, 274(1-2), 309-329.

Li, R., \& Teng, J. T. (2018). Pricing and lot-sizing decisions for perishable goods when demand depends on selling price, reference price, product freshness, and displayed stocks. European Journal of Operational Research, 270(3), 1099-1108.

Li, R., Chan, Y. L., Chang, C. T., \& Cárdenas-Barrón, L. E. (2017). Pricing and lot-sizing policies for perishable products with advance-cash-credit payments by a discounted cash-flow analysis. International Journal of Production Economics, 193(11), 578-589.

Li, R., Skouri, K., Teng, J. T., \& Yang, W. G. (2018). Seller's optimal replenishment policy and payment term among advance, cash, and credit payments. International Journal of Production Economics, 197(1), 35-42.

Li, R., Liu, Y., Teng, J. T., \& Tsao, Y. C. (2019a). Optimal pricing, lot-sizing and backordering decisions when a seller demands for an advance-cash-credit payment scheme. European Journal of Operational Research, 278(1), 283-295.

Li, R., Teng, J. T., \& Zheng, Y. (2019b). Optimal credit term, order quantity and pricing policies for perishable products when demand depends on price, expiration date, and credit period. Annals of Operations Research, 280(1-2), 377-405.

Mishra, U., Cárdenas-Barrón, L. E., Tiwari, S., Shaikh, A. A., \& Treviño-Garza, G. (2017). An inventory model under price and stock dependent demand for controllable deterioration rate with shortages and preservation technology investment. Annals of Operations Research, 254(1-2), 165-190.

Mishra, U., Tijerina-Aguilera, J., Tiwari, S., \& Cárdenas-Barrón, L. E. (2018). Retailer's joint ordering, pricingand preservation technology investment policies for a deteriorating item under permissible delay inpayments. Mathematical Problems in Engineering, Volume 2018, Article ID 6962417.

Modak, N. M., \& Kelle, P. (2019). Managing a dual-channel supply chain under price and delivery-time dependent stochastic demand. European Journal of Operational Research, 272(1), 147-161.

Pahl, J., \& Voß, S. (2014). Integrating deterioration and lifetime constraints in production and supply chain planning: A survey. European Journal of Operational Research, 238(3), 654-674.

Sarkar, B. (2012). An EOQ model with delay in payments and time varying deterioration rate. Mathematical and Computer Modelling, 55(3-4), 367-377.

Seifert, D., Seifert, R. W., \& Protopappa-Sieke, M. (2013). A review of trade credit literature: Opportunity for research in operations. European Journal of Operational Research, 231(2), 245-256.

Shi, Y., Zhang, Z., Chen, S. H., Cárdenas-Barrón, L. E., Skouri, K. (2020). Optimal replenishment decisionsfor perishable products under cash, advance, and credit payments considering carbon tax regulations. International Journal of Production Economics, 223, 107514.

Taleizadeh, A. A. (2014). An EOQ model with partial backordering and advance payments for an evaporating item. International Journal of Production Economics, 155, 185-193.

Teng, J. T. (2002). On the economic order quantity under conditions of permissible delay in payments. Journal of the Operational Research Society, 53(8), 915-918. 
Teng, J. T. (2009). Optimal ordering policies for a retailer who offers distinct trade credits to its good and bad credit customers. International Journal of Production Economics, 119(2), 415-423.

Teng, J. T., Cárdenas-Barrón, L. E., Chang, H. J., Wu, J., \& Hu, Y. (2016). Inventory lot-size policies for deteriorating items with expiration dates and advance payments. Applied Mathematical Modelling, 40(19-20), $8605-8616$.

Tiwari, S., Jaggi, C. K., Bhunia, A. K., Shaikh, A. A., \& Goh, M. (2017). Two-warehouse inventory model for non-instantaneous deteriorating items with stock-dependent demand and inflation using particle swarm optimization. Annals of Operations Research, 254(1-2), 401-423.

Tiwari, S., Cárdenas-Barrón, L. E., Shaikh, A. A., Goh, M. (2020). Retailer's optimal ordering policy for deteriorating items under order-size dependent trade credit and complete backlogging. Computers and Industrial Engineering, 139, 105559.

Wang, C., \& Huang, R. (2014). Pricing for seasonal deteriorating products with price- and ramp-type timedependent demand. Computers and Industrial Engineering, 77, 29-34.

Wang, W. C., Teng, J. T., \& Lou, K. R. (2014). Seller's optimal credit period and cycle time in a supply chain for deteriorating items with maximum lifetime. European Journal of Operational Research, 232(2), 315-321.

Wu, J., Ouyang, L. Y., Cárdenas-Barrón, L. E., \& Goyal, S. K. (2014). Optimal credit period and lot size for deteriorating items with expiration dates under two-level trade credit financing. European Journal of Operational Research, 237(3), 898-908.

Wu, J., Chang, C. T., Cheng, M. C., Teng, J. T., \& Al-khateeb, F. B. (2016). Inventory management for fresh produce when the time-varying demand depends on product freshness, stock level and expiration date. International Journal of Systems Science: Operations and Logistics, 3(3), 138-147.

Wu, J., Teng, J. T., \& Chan, Y. L. (2018a). Inventory policies for perishable products with expiration dates and advance-instant-delayed payment schemes. International Journal of Systems Science: Operations and Logistics, 5(4), 310-326.

Wu, J., Teng, J. T., \& Skouri, K. (2018b). Optimal inventory policies for deteriorating items with trapezoidaltype demand patterns and maximum lifetimes under upstream and downstream trade credits. Annals of Operations Research, 264, 459-476.

Xie, Y., Tai, A. H., Ching, W. K., Kuo, Y. H., \& Song, N. (2021). Joint inspection and inventory control for deteriorating items with time-dependent demand and deteriorating rate. Annals of Operations Research, $300,225-265$.

Zhang, A. X. (1996). Optimal advance payment scheme involving fixed pre-payment costs. Omega, 24(5), 577-582.

Zhang, Q., Tsao, Y. C., \& Chen, T. H. (2014). Economic order quantity under advance payment. Applied Mathematical Modelling, 38(24), 5910-5921.

Publisher's Note Springer Nature remains neutral with regard to jurisdictional claims in published maps and institutional affiliations. 